\title{
THE VALUE OF THE CLASSICS IN ENGINEERING EDUCATION
}

\author{
BY CHARLES P. STEINMETZ
}

Education is not the learning of a trade or profession, but is the development of the intellect and the broadening of the mind, afforded by a general knowledge of all the subjects of interest to the human race, as required to enable a man to intelligently attack and solve problems in which no previous detail experience guides, and to decide the questions arising in his intellectual, social, and industrial life by impartially weighing the different factors and judge their relative importance. These problems, and thus the educational preparation required to cope with them, are practically the same in all walks of life, and the general education of mind and intellect, required by the engineer, the lawyer, the physician, etc., thus is essentially the same. The only legitimate differences in the training for the life's work, required by the different professions, thus are those pertaining to the specific instruction and study of the details of the particular branch of human knowledge, by which the student desires to make his living.

For ages the classics, comprising the study of the Latin and Greek languages and the literature of these languages, has been the foundation of all education; but in the last two generations it has been more and more pushed into the background by the development of empirical science and its application, engineering. It is my opinion that this neglect of the classics is one of the most serious mistakes of modern education, and that the study of the classics is very important and valuable, and more so in the education of the engineer than in most other professions, for the reason that the avocation of an engineer is specially liable to make the man one sided. By dealing exclu- 
sively with empirical science and its applications, the engineer is led to forget, or never to realize, that there are other branches of human thought besides empirical science, and equally important as factors of a broad general education and intellectual development. An introduction to these other fields is best and quickest given by the study of the classics, which opens to the student other worlds entirely different from our present, the world of art and literature, of Hellas, and the world of organization and administration - and of citizenship-of Rome, and so broaden his horizon beyond anything which can be accomplished otherwise, and show relative values more in their proper proportion, and not distorted by the trend of thought of his time.

It is true that the classics are not necessary if the aim is to fit the student to ply the trade of engineer, just as that of plumber or boiler maker, and the world, and especially the United States, is full of such men which have learned the trade of engineer. But such learning of the engineering trade can hardly be called receiving an education, and certainly does not fit the man to intelligently perform his duties as citizen of the republic during the stormy times of industrial and social reorganization, which are before us.

There also is a considerable utilitarian value in the classic languages, as the terminology of science is entirely based on Latin forms with Greek and Latin roots, and while the student may memorize the terms of his profession, it is difficult, if not impracticable to memorize all the terms of science with which an educated man must be familiar as those of medicine, botany, mineralogy, etc. This however becomes easy to the student of the classic languages, to whom these terms have a meaning. To eliminate the scientific terms of objects from the language is obviously impossible, as the "common" or "English" names usually are different in different localities, if they exist at all, and thereby indefinite.

The modern languages are not in the same class with the classic languages, as they open to the student no new world, no field of thought appreciably different from our own, and I therefore consider them of practically no educational value. Their utilitarian value to the college student is negligible, as due to the limited time, the absence of practice, and the large number of other more important subjects of study, very few of the college graduates retain even a rudiment of their knowledge of modern languages, and even those few only because they are especially interested in them, have occasion to practice them, 
and therefore would probably have learned them outside of college. To the engineer particularly, the knowledge of foreign modern languages offers no appreciable help in following the engineering progress of other countries, as practically all that is worth reading is translated into English either in full or in abstract, and engineering publications written in a foreign language are closed to the reader even if he has some knowledge of the language, by his lack of knowledge of the technical terminology of the foreign language.

Since the modern languages have no appreciable educational value, they should be dropped from the engineering curriculum of the college, as their retention violates the principle of the modern college curriculum, to restrict, due to the limited available time, the instruction to those subjects which the student can not acquire outside of the college by self study, or can acquire only under great difficulties. Modern languages do not belong to this class, but are learned just as easily, if not more so, by self study and conversation.

Referring to the classics however; it is true that the methods of their teaching are not the most efficient, and especially the classic literature with which the student is familiarized, is not selected so as to offer the greatest educational value in broadening the student's view, nor so as to attract and retain his interest as much as possible, but rather seems to be the result of survival from previous times.

Thus in Latin the story of war and conquest, of the victory of military organization over mere bravery, in Caesaris de bello Gallico, is interesting and instructive, while the Civil war is of less interest. Even to-day Ciceronis de officiis is well worth reading, while Ad Catilinam is stupefying to the intellect, since any intelligent boy must ask why did the "man afraid of his shadow" not have Catilina arrested and executed for high treason.

In Latin poetry selections from Ovidii Metamorphoses are very easy reading, and are a valuable introduction to the classic metre, and interesting in the parallelism of the myths of the classic world with those of other races (the flood etc.), but it is hard to understand the retention of the uninteresting plagiarism of the courtier Virgil in the curriculum, while the most important, in his educational value, and most interesting poet, Horaz, is not read at all in most college curricula. Of all Roman writers, Horaz probably exerts the most broadening influence on the intellect when read under an intelligent instructor; the change from the distortion in which the relative 
values of persons and things appear to their contemporaries, to the proper proportion in the perspective of history, probably is nowhere so sharply demonstrated as in the relation between the "libertino patre natus" and his " protector" and "patron" Maecenas, whose name has escaped oblivion merely by his favorite's favor, while Horaz promises immortality to whatever he addresses, and confers it (ad fontem Bandusiam). The reading of Horaz probably is the best remedy for discouragement resulting from lack of appreciation of one's efforts, as the engineer and the inventor very often has reason to feel. Also especially the American, who is generally liable to take himself - too seriously, might benefit from the sentiment expressed in Ad Leuconoen. In short almost every one of Horaz's poems is interesting and instructive and conveys a moral which we may well listen to.

In Greek prose, Xenophontis Anabasis is interesting and instructive in many respects, and may well be followed by the student with maps of the country traversed by the ten thousand. Selections from Lucian possibly are the nearest approach to Horaz in their broadening influence. The Greek drama probably is beyond the scope of reading which can be attempted in a general college course, and also appears to me less important now, where in the modern northern drama we have similar tendencies exhibited. The easy dialect of the kovv $\eta$ however is within the reach of the student, and at least a part of the new testament may be read in the original and its value can hardly be overestimated in showing the meaningless nature of theological controversies on words of an imperfect translation. The greatest work of the literature of Hellas however is Homer; and here again in many American schools the Iliad only is read, possibly from the mistaken notion that it is easier reading, while the far more interesting Odysee is slighted, though the latter with its tales of travel and adventure, with giants and monsters, should especially appeal to the American boy, and is of far greater interest and educational value in its minute description of everyday life at the early dawn of human history, in its pictorial expressions of times and occupations, of the time of the day, the coming of night, the dawn, etc. Nowhere possibly is found such a vivid description of omnipotence as in Homer's:

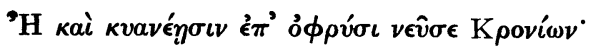

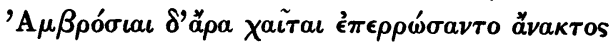

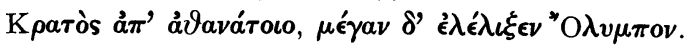

